\title{
Detection of Minimal Residual Disease by Flow Cytometry for Patients with Multiple Myeloma Submitted to Autologous Hematopoietic Stem Cell Transplantation
}

\author{
Suzane Dal Bó, ${ }^{1}$ Annelise Pezzi, ${ }^{2}$ Bruna Amorin, ${ }^{2}$ Vanessa Valim, \\ Rosane Isabel Bittencourt, ${ }^{3}$ and Lucia Silla ${ }^{2,3}$ \\ ${ }^{1}$ Unit of Hematology, Clinical Pathology Service, Hospital de Clínicas de Porto Alegre, 90035-903 Porto Alegre, RS, Brazil \\ ${ }^{2}$ Laboratory of Cell Culture and Molecular Analysis of Hematopoietic Cells, Hospital de Clínicas de Porto Alegre, \\ 90035-903 Porto Alegre, RS, Brazil \\ ${ }^{3}$ Hematology and Bone Marrow Transplantation, Hospital de Clínicas de Porto Alegre, 90035-903 Porto Alegre, RS, Brazil
}

Correspondence should be addressed to Lucia Silla; 1silla@hcpa.ufrgs.br

Received 29 April 2013; Accepted 29 May 2013

Academic Editors: A. Bosly and A. Gatt

Copyright (C) 2013 Suzane Dal Bó et al. This is an open access article distributed under the Creative Commons Attribution License, which permits unrestricted use, distribution, and reproduction in any medium, provided the original work is properly cited.

\begin{abstract}
The treatment strategy in multiple myeloma (MM) is to get complete remission followed by high-dose chemotherapy and autologous Hematopoietic Stem Cell Transplantation (HSCT). Neoplastic Plasma Cells (NPCs) are CD $45^{-/ \text {dim }}, \mathrm{CD} 8^{+ \text {high }}, \mathrm{CD} 138^{+}$, $\mathrm{CD} 9^{-}$, and $\mathrm{CD} 56^{\text {+high }}$ in most cases. The description of this immunophenotype is of major importance as it leads to the correct identification of minimal residual disease (MRD). Samples from 44 Patients were analyzed prospectively in this study. We analyzed if the presence of MRD at three months after HSCT was predictive of relapse or death. There were 40 evaluable patients of whom $16 / 40$ patients had MRD at three moths after HSCT and there were none in cytological relapse. The mean overall survival (OS) was 34 months and disease-free survival (RFS) was 28 months after HSCT. There was no significant difference in the log rank analysis comparing OS and the presence of MRD $(P=0,611)$ and RFS $(P=0,3106)$. Here, we demonstrate that three color flow cytometry (FCM) is more sensitive for MDR evaluation than cytological analyzes. However, based in our data we can not affirm that MRD is a good predictor of MM relapse or death. In conclusion, our results could be attributed to a short followup, small sample size, and over most to the inability of a three-color FCM to detect the NPC population.
\end{abstract}

\section{Introduction}

Multiple myeloma (MM) is a malignant disease characterized by an increase in the number of clonal plasma cells in the bone marrow $(\mathrm{BM})$ and the presence of monoclonal protein, the M-protein, usually IgG or IgA, in blood, urine, or both [1]. Clinical signs are different combinations of bone marrow plasma cell infiltration with or without impaired hematopoiesis [2]; production of monoclonal immunoglobulin with decrease in the production of normal, polyclonal gammaglobulins; osteolytic lesions [3,4], hypercalcemia, and renal failure. Since the clinical picture is heterogeneous, diagnostic criteria are mandatory in routine clinical practice being the Durie and Salmon staging criteria the gold standard to diagnose and stage MM. These criteria combine hemoglobin $2 \mathrm{~g} / \mathrm{dL}$ below the normal level for the laboratory or if the haemoglobin falls to $10 \mathrm{~g} / \mathrm{dL}$, a serum calcium level $>0.25 \mathrm{mmol} / \mathrm{L}$, the serum creatinine $>173 \mathrm{mmol} / \mathrm{L}, \mathrm{M}$-protein in serum $>30 \mathrm{~g} / \mathrm{L}$, and bone involvement $[5,6]$. A finding of $10 \%$ or more plasma cells in bone marrow aspirate (BMA) is one of the three major criteria for the diagnosis of MM. For risk stratification, apart from the Durie and Salmon criteria, the International Myeloma Foundation has recently recommended the International Staging System (ISS), a new set of criteria based on the values of $\beta_{2}$ microglobulin and serum albumin [7]. Because of the heterogeneous distribution in the BM, the variation of plasma cell percentage is not a criterion to evaluate response to treatment, but 


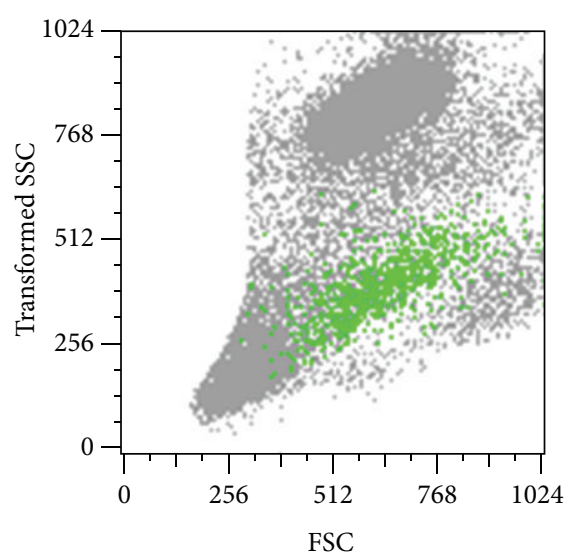

(a)

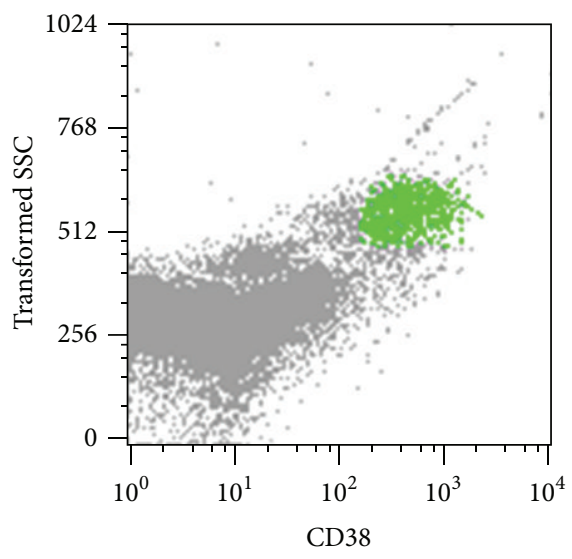

(d)

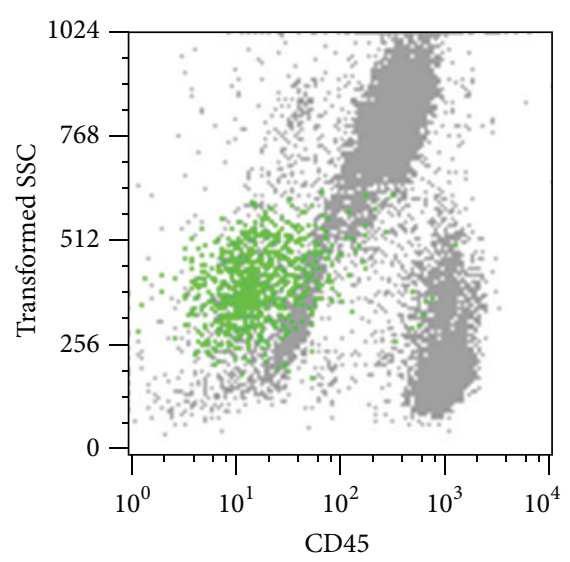

(b)

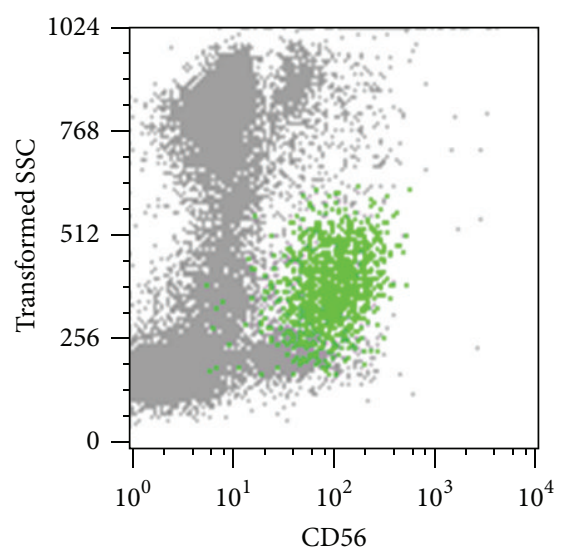

(e)

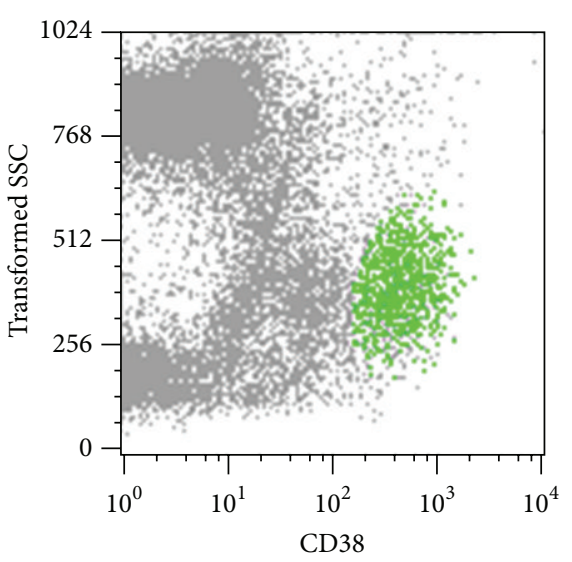

(c)

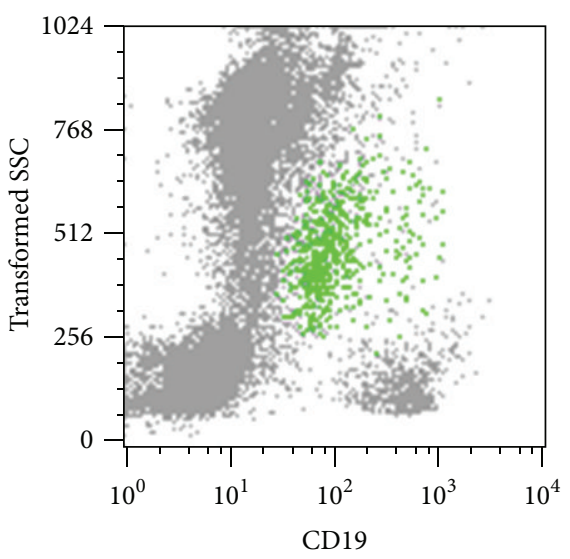

(f)

FIGURE 1: Immunophenotypic characteristic plasma cell (painted in green). (a) SSC $\times$ FSC characteristics of normal PC and neoplastic PC, (b) $\mathrm{CD} 45^{-/ \text {dim }}$ characteristics of neoplastic PC, (c) CD $38^{\text {thigh }}$ characteristics of normal and neoplastic PC, (d) CD138 $\times$ CD 38 characteristics of normal PC and neoplastic plasma cell, (e) CD56 $6^{\text {thigh }}$ characteristics of neoplastic PC, (f) CD19 negative characteristics of neoplastic PC. *TSSC (transformed SSC_-Paint a Gate).

the detection of less than $5 \%$ of plasma cells, associated with the disappearance of other signs and symptoms of the disease, is generally accepted as complete remission [8].

Plasma cells are characterized by the presence of cytoplasmic immunoglobulin and, on the cell surface, CD38 and CD138 antigens [8-12]. The CD38 is widely expressed in the hematopoietic lineage; flow cytometry (FCM) has shown that the intensity of CD38 fluorescence in plasma cells is much higher than in the other hematopoietic cells, and this strong reactivity was converted into a specific marker for plasma cells. CD138 (syndecan-1) is a specific marker, both for normal and neoplastic plasma cells since it is not found in the other hematopoietic cells [13-15]. The CD38 and CD138 combination in flow cytometry is widely used to characterize both normal and neoplastic plasma cells [9-11, 16-18]. At the same time, neoplastic plasma cells lose the CD19, CD20, and CD22 markers in about $85 \%$ of the patients with MM $[14,15,19]$ and there is little or no expression of CD45 in about $90 \%$ of the cases [20]. Adhesion molecules apparently involved in the pathogenesis of MM, such as the CD56 [8], are found in about 70\% [19] of the patients with MM and disappear in advanced stages of the disease [21,22]. Another well-established characteristic of plasma cells is their size properties (forward scatter-FSC) and internal complexity (side scatter-SSC), which are revealed in the analysis by flow cytometry [8]. The combination of these characteristics by multiparametric immunophenotyping allows us to study the coexpression of these molecules on the cell surface, to detect malignant plasma cells, and to differentiate MM from other monoclonal gammopathies. In summary, differently from other normal plasma cells $\left(\mathrm{CD} 19^{+}, \mathrm{CD} 45^{+}, \mathrm{CD} 38^{\text {thigh }}\right.$, $\mathrm{CD} 138^{+}$, and $\left.\mathrm{CD} 56^{-}\right)$, neoplastic plasma cells are $\mathrm{CD} 45^{-/ \mathrm{dim}}$, $\mathrm{CD} 38^{\text {+high }}, \mathrm{CD} 138^{+}, \mathrm{CD} 19^{-}$, and CD56 ${ }^{\text {thigh }}$ (Figure 1) in most cases. The identification of this immunophenotype has substantial value in the distinction between MM and monoclonal gammopathy of undetermined significance (MGUS), as well as in the assessment of minimal residual disease (MRD) $[8,16,19,23-25]$.

MRD may be defined as the presence of neoplastic cells in patients that are clinically in complete remission (CR), detected by more sensitive methods than light microscopy, 
such as FCM [10, 17] or polymerase chain reaction (PCR) [26, 27]. Methods to detect residual tumor cells or early relapses without clinical signs have been widely used in an attempt to initiate adequate therapy for MRD as early as possible after transplantation [28]. The role of the presence and amount of MRD is well established in chronic myeloid leukemia (CML) [29] and in acute lymphoid leukemia (ALL) in children [30]. In both, the amount of MRD measured using quantitative PCR for CML e LLA and FCM for ALL is associated with disease relapse.

The best treatment strategy in MM is to get CR followed by high-dose chemotherapy and autologous Hematopoietic Stem Cell Transplantation (HSCT) [31]. Thirty-one to 51\% of these patients achieve CR [32], and this is followed by higher rates of disease-free or progression-free survival when compared with patients that do not achieve CR [33]. In this scenario, however, of the patients in CR only a few achieve molecular remission eventually relapsing as consequence of residual disease [34]. The International Myeloma Working Group has defined stringent complete response (sCR), CR, very good partial remission (VGPR), and partial remission (PR) as a tool to compare and analyze treatment results [35]. Briefly, sCR is defined as CR plus normal free light chains (FLC ratio) and absence of phenotypically aberrant plasma cells-PC in bone marrow with a minimum of 3000 total PC analyzed by multiparametric flow cytometry (with $>4$ colors) $\mathrm{CR}$ is defined as absence of $\mathrm{M}$ component (serum and urine) and $\leq 5 \%$ plasma cells in the BM; VGPR is serum and urine $\mathrm{M}$ component detectable by immunofixation but not on electrophoresis or $90 \%$ or greater reduction in serum M-protein plus urine M-protein level $<100 \mathrm{mg}$ per $24 \mathrm{~h}$ and $\mathrm{PR} \geq 50 \%$ reduction of serum M-protein and reduction in $24 \mathrm{~h}$ urinary M-protein by $\geq 90 \%$ on to $<200 \mathrm{mg}$ per $24 \mathrm{~h}$.

Molecular $[9,10,18,36,37]$ or FCM $[9,10,17,24,26,36]$ methods have been used to detect MRD in MM, but its clinical importance is still being evaluated since most studies included only a small number of patients [10, 18, 24].

This prospective study evaluated MRD detection using FCM in patients with MM submitted to high-dose chemotherapy followed by autologous Hematopoietic Stem Cell Transplantation (HSCT), at the Hematology and Bone Marrow Transplantation Unit at Hospital de Clínicas de Porto Alegre, Rio Grande do Sul, Brazil.

\section{Material and Methods}

2.1. Patients and Treatment. Patients with MM who achieved CR, VGPR, or PR to high-dose chemotherapy (MEL 200melphalan $100 \mathrm{mg} / \mathrm{m}^{2} /$ day [D-3] and melphalan $100 \mathrm{mg} / \mathrm{m}^{2} /$ day [D-2]) followed by autologous HSCT between December 2005 and May 2009 were included in this study. We evaluated the patients at 3 months after HSCT and the laboratory reevaluation was performed and bone marrow was collected for cytological and immunophenotypic studies. This study was approved by the Ethics Committee of HCPA. Written informed consent was obtained
TABLE 1: Characteristics of MM patients enrolled in the study between December 2005 and May 2009.

\begin{tabular}{lcc}
\hline Total patients $(n)$ & 44 & \\
Age, years median (min-max) & 55,5 & $52,2-64$ \\
Sex, M/F & $21 / 23$ & \\
Immunoglobulin isotype (\%) & & \\
$\quad$ IgG & 61,4 & \\
IGA & 18,20 & \\
Kappa light chain & 15,90 & \\
Lambda light chain & 4,5 & \\
Response before TCTH $n$ (\% of total) & & 27,3 \\
CR & 12 & 43,2 \\
VGPR & 19 & 29,5 \\
$\quad$ PR & 13 & \\
Response after TCTH $n$ (\% of total) & & 32,6 \\
CR & 14 & 36,4 \\
VGPR & 16 & 4,7 \\
PR & 2 & 2,3 \\
Not known & 1 & 7,0 \\
Relapse & 3 & 18,6 \\
Dead & 8 & $9-43$ \\
Follow-up time, months (mean) & 18 & \\
\hline
\end{tabular}

from every participant and the data were analyzed anonymously according to Declaration of Helsinki for human studies.

2.2. Immunophenotypic Studies. The bone marrow samples were prepared and analyzed within 24 hours. Each test tube received $100 \mu \mathrm{L}$ of $\mathrm{BM}$, which corresponded to about $10^{6}$ leukocytes; samples were incubated with $5 \mu \mathrm{L}$ of each monoclonal antibody marked with fluorochromes (FITC, PE, and PECY5/PERCP), according to the panel below, and incubated for 15 minutes in the dark; the lysis was performed using Facslyse (BD Dickinson, San Jose, CA, USA) for 15 minutes, centrifuged, washed twice with PBS (phosphate buffer saline), and resuspended with PBS plus paraformaldehyde. The cells were acquired in a 3-color FacsCalibur BD Flow Cytometer 10 (Becton Dickinson, San Jose, CA).

The monoclonal antibodies used were CD38, CD138, CD19, CD56, and CD45 in the following combination: CD45/ CD138/CD38; CD19/CD138/CD38; CD38/CD56/CD138; and CD45/CD3. Samples were acquired twice: first, 20000 events, and second, using the Gates acquisition system, 50000 to 450000 events were acquired in the CD38 gate. The acquisition software used was Cellquest BD (Becton Dickinson, San Jose, CA, USA). In the gate acquisitions, the total number of events acquired in the cytometer was recorded for the final calculation of the number of cells with phenotypes of interest. The analyses were performed using the Paint-AGate PRO software (Becton Dickinson, San Jose, CA, USA). Neoplastic plasma cells were defined as $\mathrm{CD} 45^{-/ \mathrm{dim}} \mathrm{CD} 138^{+}$, $\mathrm{CD} 38^{\text {thigh }}$, and $\mathrm{CD} 19^{-} \mathrm{CD} 56^{+/-}$. CD3 was utilized to exclude contaminating events and to detect peripheral blood in the sample. The analytical strategy was to choose positive 
TABLE 2: Results of patients at 3 months.

\begin{tabular}{|c|c|c|c|c|}
\hline & MRD (3 months) & Status (preTCTH) & Status (end of study) & Immunoglobulin type \\
\hline 1 & - & VGPR & $\mathrm{D}$ & IgG \\
\hline 2 & - & $\mathrm{CR}$ & $\mathrm{CR}$ & $\operatorname{IgG}$ \\
\hline 3 & - & CR & $\mathrm{CR}$ & IgG \\
\hline 4 & - & VGPR & $\mathrm{D}$ & $\operatorname{IgG}$ \\
\hline 5 & - & $\mathrm{CR}$ & CR & Kappa light chain \\
\hline 6 & - & PR & $\mathrm{D}$ & $\operatorname{Ig} \mathrm{A}$ \\
\hline 7 & + & PR & VGPR & IgG \\
\hline 8 & - & PR & VGPR & $\operatorname{IgA}$ \\
\hline 9 & - & $\mathrm{CR}$ & $\mathrm{CR}$ & Kappa light chain \\
\hline 10 & - & VGPR & $\mathrm{R}$ & Lambda light chain \\
\hline 11 & + & PR & $\mathrm{D}$ & $\operatorname{IgG}$ \\
\hline 12 & - & $\mathrm{CR}$ & VGPR & IgG \\
\hline 13 & - & $\mathrm{CR}$ & $\mathrm{CR}$ & IgG \\
\hline 14 & - & VGPR & PR & $\operatorname{IgG}$ \\
\hline 15 & + & PR & $\mathrm{D}$ & $\operatorname{Ig} \mathrm{A}$ \\
\hline 16 & + & PR & $\mathrm{R}$ & $\operatorname{Ig} \mathrm{A}$ \\
\hline 17 & - & CR & $*$ & $\operatorname{IgG}$ \\
\hline 18 & + & VGPR & CR & $\operatorname{IgG}$ \\
\hline 19 & + & $\mathrm{CR}$ & VGPR & $\operatorname{IgG}$ \\
\hline 20 & + & $\mathrm{CR}$ & $\mathrm{CR}$ & $\operatorname{IgG}$ \\
\hline 21 & + & CR & CR & Lambda light chain \\
\hline 22 & + & VGPR & VGPR & $\operatorname{IgG}$ \\
\hline 23 & + & $\mathrm{PR}$ & VGPR & IgG \\
\hline 25 & - & VGPR & VGPR & Kappa light chain \\
\hline 28 & - & PR & $\mathrm{D}$ & IgG \\
\hline 30 & - & VGPR & CR & $\operatorname{IgG}$ \\
\hline 31 & - & CR & CR & IgG \\
\hline 32 & - & VGPR & VGPR & IgG \\
\hline 33 & - & $\mathrm{CR}$ & VGPR & $\operatorname{IgG}$ \\
\hline 35 & + & PR & $\mathrm{R}$ & $\operatorname{IgA}$ \\
\hline 36 & - & PR & VGPR & Kappa light chain \\
\hline 37 & - & PR & $\mathrm{D}$ & $\operatorname{IgA}$ \\
\hline 38 & + & VGPR & VGPR & $\operatorname{IgG}$ \\
\hline 39 & + & VGPR & VGPR & Kappa light chain \\
\hline 40 & + & VGPR & VGPR & $\operatorname{Ig} \mathrm{A}$ \\
\hline 41 & + & PR & $\mathrm{D}$ & $\operatorname{IgA}$ \\
\hline 42 & + & PR & $\mathrm{PR}$ & $\operatorname{Ig} A$ \\
\hline 43 & - & VGPR & VGPR & $\operatorname{IgG}$ \\
\hline 44 & - & VGPR & VGPR & $\operatorname{Ig} \mathrm{A}$ \\
\hline 45 & - & VGPR & VGPR & IgG \\
\hline
\end{tabular}

(D) Died; (R) relapse; (PR) partial remission; (VGPR) very good PR; (CR) complete remission.

(+) FCM $>0,01 \%$ neoplastic PC immunophenotype.

(-) FCM $\leq 0,01 \%$ PC neoplastic immunophenotype.

events for CD38 and CD138 and to check the expression of CD45, CD56, and CD19. A minimum of 50 positive events, considering the sum of the three tubes under analysis, was required to ensure analysis. MRD was defined as the presence of neoplastic plasma cells higher than $0.01 \%$ of the sample as described in previous studies $[8,18,25]$.
Cytological examination was done in BM cells smear stained with MayGrunwald Giemsa including at least 500 nucleated cells.

The end points of the study were to evaluate a possible relationship between the presence of $\mathrm{MRD}$, relapse, or death in relapse during the period of the study. 


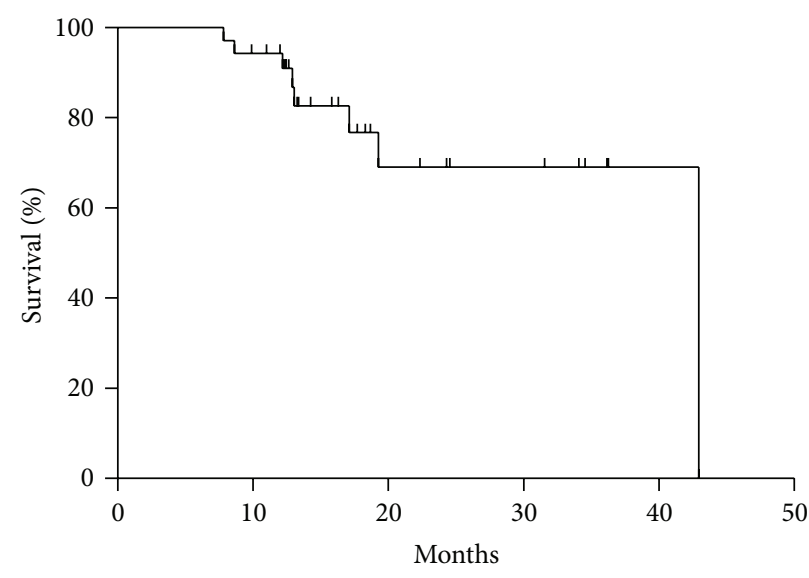

(a) OS

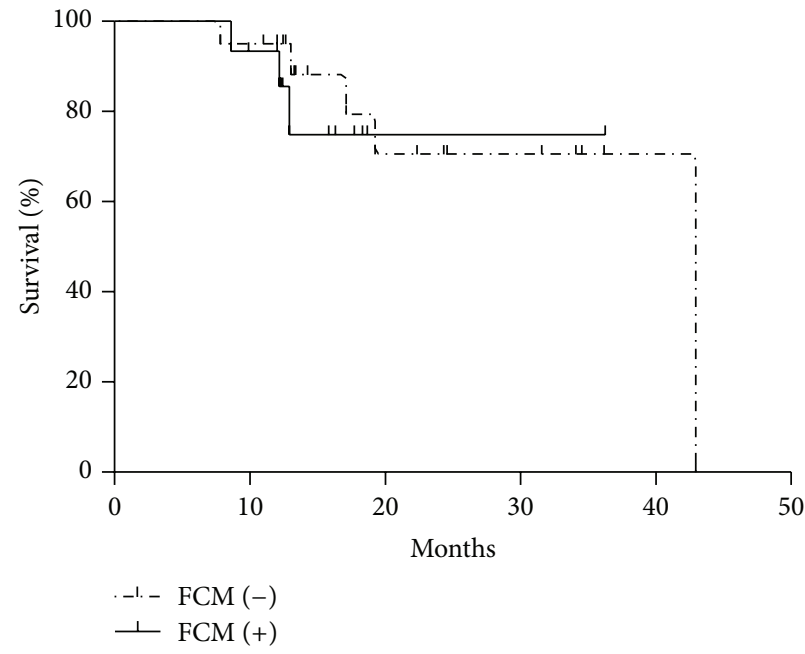

(c) OS $P=0,6114$

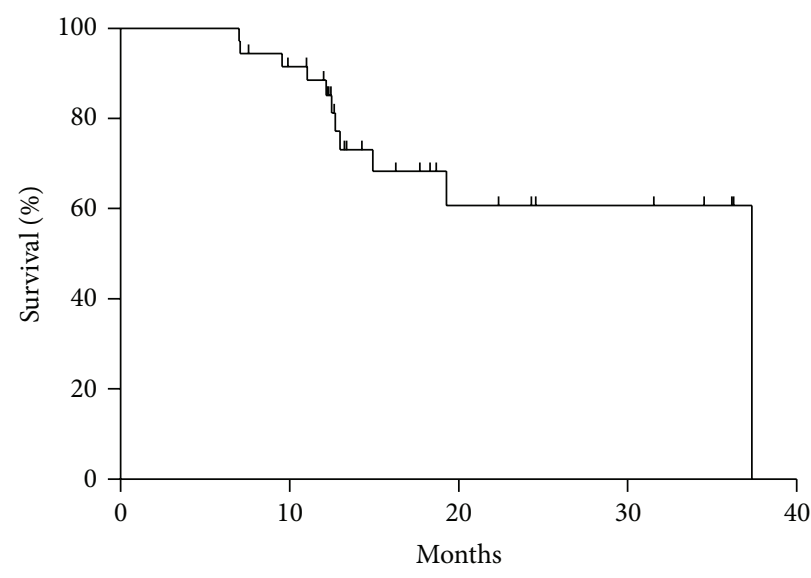

(b) DFS

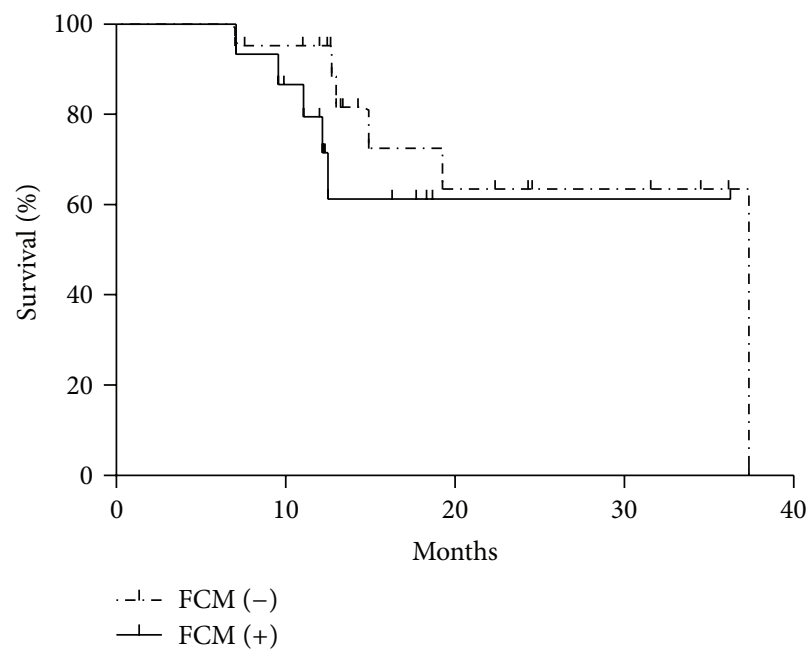

(d) DFS $P=0,3106$

FIGURE 2: (a) Overall survival (OS), (b) disease-free survival (DFS), (c) overall survival curves according to the DRM evaluation, (d) diseasefree survival curves according to the DRM evaluation.

2.3. Statistical Methods. A descriptive analysis of the data was accomplished through median for the quantitative variables, while the categorical variables were represented through frequency and percentile. For evaluation of the overall survival (OS) and disease-free survival (DFS) Kaplan-Meier was utilized, comparing the groups through the log rank test. The data was analyzed in SPSS 12.0 and the value of adopted alpha was $5 \%$.

\section{Results}

Samples from 44 patients (21 men) were analyzed prospectively in this study. Median age at the time of HSCT was 55 years [percentile-25 (52, 25 years) and 75 (64 years)] (Table 1).

We analyzed if the presence of MRD at three months after HSCT was predictive of relapse or death. There were 40 evaluable patients of whom 16/40 patients had MRD at three months after HSCT and there were none in cytological relapse
(Table 2). The mean overall survival (OS) was 34 months and disease-free survival (DFS) was 28 months (Kaplan-Meier curve) after HSCT. There was no significant difference in the log rank analysis comparing OS and the presence of MRD $(P=0,611)$ and relapse-free survival (RFS) $(P=0,3106)$ (Figure 2). Although not all the patients were evaluated for MRD in all time points, our results showed FCM MDR evaluation to be more sensitive than BM, in none of these points; however, they were MRD predictive of relapse or death of MM.

\section{Discussion}

Pérez-Persona et al. [38] demonstrated that the ratio between the proportion of abnormal and normal plasma cell as identified by FCM significantly correlates with risk for disease progression. A better long-term outcome was observed in patients with a low level of MM plasma cells as detected by FCM prior to autologous HSCT [24]. Early reappearance of 
MM plasma cells after high dose chemotherapy was related to a shorter PFS [10, 33]. Paiva et al. [39] showed in a large number of uniformly treated MM, 297 patients, that FCM MRD status at day 100 after autologous HSCT was the most relevant prognostic factor for MM.

Here we showed that in spite of being significantly more sensitive than cytology to detect MRD in MM, FCMmeasured by the identification of plasma cells $\mathrm{CD} 45^{-/ \mathrm{dim}}$ $\mathrm{CD} 138^{+}, \mathrm{CD} 38^{\text {+high }}$, and $\mathrm{CD} 19^{-} \mathrm{CD}^{+} 6^{+}[13-15,23]$-did not predict for relapse or death from MM in our group of patients.

The correct quantification of plasma cells in bone marrow is fundamental for the diagnosis of MM [35]. Multiparametric flow cytometry is a method to monitor minimal residual disease and to evaluate treatment results [16]. The use of this method will eventually become more frequent in this context and, therefore, demand approaches that define specificity and sensitivity to ensure the use of an adequate quality control program. The combination of at least four colors is currently the best recommendation to monitor minimal residual disease in MM [39]. However, for most laboratories in developing countries, equipment that reads four colors simultaneously is still uncommon due to high costs. Discrepancies between cytological evaluation and FCM and their impact as predictors of relapse in MM could be attributed to the ability of FCM to detect malignant plasma cells as compared to BM cytology.

Our results could be attributed to a short followup, small sample size, and possibly, to the inability of a three-color parametric flow cytometry to correctly detect the malignant plasma cell population. We showed however that, in our hands, FCM is a high sensitive method for MRD detection. Augmenting the number of patients, the follow-up period, and the utilization of more then three colors combination for FCM will likely improve our results. The use of MRD burden for the early institution of treatment, as well as the use of novel drugs with a better remission quality will likely be widely utilized in the treatment of MM.

\section{Acknowledgment}

The study received financial support from the Research and Event Incentive Fund of Hospital de Clínicas de Porto Alegre (FIPE-HCPA). There is no conflict of interests to be declared.

\section{References}

[1] R. Bataille and J. L. Harousseau, "Multiple myeloma," The New England Journal of Medicine, vol. 336, no. 23, pp. 1657-1665, 1997.

[2] B. Barlogie, J. Schaughnessy, N. Munshi, and J. Epstein, "Plasma cell myeloma," in Williams Hematology, E. Beutler, M. A. Lichtman, B. S. Coller, and T. I. Kipps, Eds., pp. 1279-1298, Mac Graw Hill, New York, NY, USA, 6 edition, 2001.

[3] S. V. Rajkumar, M. A. Gertz, R. A. Kyle, and P. R. Greipp, "Current therapy for multiple myeloma," Mayo Clinic Proceedings, vol. 77, no. 8, pp. 813-822, 2002.

[4] G. R. Mundy, "Investigation, prophilaxis, and treatment of bone Disease. Internacional Myeloma Gand Round," The Lancet Oncology, vol. 2, pp. 573-574, 2001.
[5] B. G. M. Durie and S. E. Salmon, "A clinical staging system for multiple myeloma. Correlation of measured myeloma cell mass with presenting clinical features, response to treatment, and survival," Cancer, vol. 36, no. 3, pp. 842-854, 1975.

[6] R. A. Kyle, J. A. Child, K. Anderson et al., "Criteria for the classification of monoclonal gammopathies, multiple myeloma and related disorders: a report of the International Myeloma Working Group," British Journal of Haematology, vol. 121, no. 5, pp. 749-757, 2003.

[7] P. R. Greipp, J. San Miguel, B. G. M. Durie et al., "International staging system for multiple myeloma," Journal of Clinical Oncology, vol. 23, no. 15, pp. 3412-3420, 2005.

[8] J. F. San Miguel, N. C. Gutiérrez, G. Mateo, and A. Orfao, "Conventional diagnostics in multiple myeloma," European Journal of Cancer, vol. 42, no. 11, pp. 1510-1519, 2006.

[9] M. Lioznov, A. Badbaran, B. Fehse, U. Bacher, A. R. Zander, and N. M. Kröger, "Monitoring of minimal residual disease in multiple myeloma after allo-SCT: flow cytometry vs PCR-based techniques," Bone Marrow Transplantation, vol. 41, no. 10, pp. 913-916, 2008.

[10] A. C. Rawstron, F. E. Davies, R. Dasgupta et al., "Flow cytometric disease monitoring in multiple myeloma: the relationship between normal and neoplastic plasma cells predicts outcome after transplantation," Blood, vol. 100, no. 9, pp. 3095-3100, 2002.

[11] X. Zhao, Q. Huang, M. Slovak, and L. Weiss, "Comparison of ancillary studies in the detection of residual disease in plasma cell myeloma in bone marrow," American Journal of Clinical Pathology, vol. 125, no. 6, pp. 895-904, 2006.

[12] J. Almeida, A. Orfao, G. Mateo et al., "Immunophenotypic and DNA content characteristics of plasma cells in multiple myeloma and monoclonal gammopathy of undetermined significance," Pathologie Biologie, vol. 47, no. 2, pp. 119-127, 1999.

[13] J. E. San Miguel, R. Garcia-Sanz, M. Gonzalez, and A. Orfao, "Immunophenotype and DNA cell content in multiple myeloma," Bailliere's Clinical Haematology, vol. 8, no. 4, pp. 735759, 1995

[14] J. Almeida, A. Oreao, M. Ocqueteau et al., "High-sensitive immunophenotyping and DNA ploidy studies for the investigation of minimal residual disease in multiple myeloma," British Journal of Haematology, vol. 107, no. 1, pp. 121-131, 1999.

[15] H. Harada, M. M. Kawano, N. Huang et al., "Phenotypic difference of normal plasma cells from mature myeloma cells," Blood, vol. 81, no. 10, pp. 2658-2663, 1993.

[16] A. C. Rawstron, A. Orfao, M. Beksac et al., "Report of the European Myeloma Network on multiparametric flow cytometry in multiple myeloma and related disorders," Haematologica, vol. 93, no. 3, pp. 431-438, 2008.

[17] J. F. S. San Miguel, J. Almeida, G. Mateo et al., "Immunophenotypic evaluation of the plasma cell compartment in multiple myeloma: a tool for comparing the efficacy of different treatment strategies and predicting outcome," Blood, vol. 99, no. 5, pp. 1853-1856, 2002.

[18] M. E. Sarasquete, R. García-Sanz, D. González et al., "Minimal residual disease monitoring in multiple myeloma: a comparison between allelic-specific oligonucleotide real-time quantitative polymerase chain reaction and flow cytometry," Haematologica, vol. 90, no. 10, pp. 1365-1372, 2005.

[19] G. M. Manzanera, J. F. S. M. Izquierdo, and A. O. de Matos, "Immunophenotyping of plasma cells in multiple myeloma," Methods in molecular medicine, vol. 113, pp. 5-24, 2005. 
[20] A. C. Rawstron, R. G. Owen, F. E. Davies et al., "Circulating plasma cells in multiple myeloma: characterization and correlation with disease stage," British Journal of Haematology, vol. 97, no. 1, pp. 46-55, 1997.

[21] A. Rawstron, S. Barrans, D. Blythe et al., "Distribution of myeloma plasma cells in peripheral blood and bone marrow correlates with CD56 expression," British Journal of Haematology, vol. 104, no. 1, pp. 138-143, 1999.

[22] B. Van Camp, B. G. M. Durie, C. Spier et al., "Plasma cells in multiple myeloma express a natural killer cell-associated antigen: CD56 (NKH-1; Leu-19)," Blood, vol. 76, no. 2, pp. 377382,1990

[23] P. Lin, R. Owens, G. Tricot, and C. S. Wilson, "Flow cytometric immunophenotypic analysis of 306 cases of multiple myeloma," American Journal of Clinical Pathology, vol. 121, no. 4, pp. 482488, 2004.

[24] H. Liu, C. Yuan, J. Heinerich et al., "Flow cytometric minimal residual disease monitoring in patients with multiple myeloma undergoing autologous stem cell transplantation: a retrospective study," Leukemia and Lymphoma, vol. 49, no. 2, pp. 306-314, 2008.

[25] R. G. Owen, A. C. Rawstron, F. W. Cremer et al., "Minimal residual disease monitoring in multiple myeloma: flow cytometry is the method of choice," British Journal of Haematology, vol. 128, no. 5, pp. 732-734, 2005.

[26] P. Corradini, M. Cavo, H. Lokhorst et al., "Molecular remission after myeloablative allogeneic stem cell transplantation predicts a better relapse-free survival in patients with multiple myeloma," Blood, vol. 102, no. 5, pp. 1927-1929, 2003.

[27] L. F. Christine, J. Harrison, A. Victor Hoffbrand, and M. N. Potter, "Investigation of minimal residual disease in childhood and adult acute lymphoblastic leukaemia by molecular analysis," British Journal of Haematology, vol. 105, no. 1, pp. 7-24, 1999.

[28] B. P. Simões, "Avaliação de doença residual mínima pós transplante de medula óssea," Medicina Medicina, vol. 33, pp. 433442, 2000.

[29] I. Iacobucci, G. Saglio, G. Rosti et al., "Achieving a major molecular response at the time of a complete cytogenetic response (CCgR) predicts a better duration of CCgR in imatinib-treated chronic myeloid leukemia patients," Clinical Cancer Research, vol. 12, no. 10, pp. 3037-3042, 2006.

[30] E. Coustan-Smith, R. C. Ribeiro, P. Stow et al., "A simplified flow cytometric assay identifies children with acute lymphoblastic leukemia who have a superior clinical outcome," Blood, vol. 108, no. 1, pp. 97-102, 2006.

[31] B. Barlogie, R. A. Kyle, K. C. Anderson et al., "Standard chemotherapy compared with high-dose chemoradiotherapy for multiple myeloma: final results of phase III US intergroup trial S9321," Journal of Clinical Oncology, vol. 24, no. 6, pp. 929936, 2006.

[32] R. P. Falcão and L. F. F. Dalmazzo, "O valor da Imunofenotipagem para o diagnóstico do mieloma múltiplo e na avaliação da doença residual mínima," RevBrasde Hematol e Hemoter, vol. 29, no. 1, pp. 3-9, 2007.

[33] F. E. Davies, P. D. Forsyth, A. C. Rawstron et al., "The impact of attaining a minimal disease state after high-dose melphalan and autologous transplantation for multiple myeloma," British Journal of Haematology, vol. 112, no. 3, pp. 814-819, 2001.

[34] C. S. Zent, C. S. Wilson, G. Tricot et al., "Oligoclonal protein bands and Ig isotype switching in multiple myeloma treated with high-dose therapy and hematopoietic cell transplantation," Blood, vol. 91, no. 9, pp. 3518-3523, 1998.
[35] B. G. M. Durie, J.-L. Harousseau, J. S. Miguel et al., "International uniform response criteria for multiple myeloma," Leukemia, vol. 20, no. 9, pp. 1467-1473, 2006.

[36] F. E. Davies, A. C. Rawstron, R. G. Owen, and G. J. Morgan, "Minimal residual disease monitoring in multiple myeloma," Best Practice and Research, vol. 15, no. 1, pp. 197-222, 2002.

[37] R. G. Owen, R. J. Johnson, A. C. Rawstron et al., "Assessment of IgH PCR strategies in multiple myeloma," Journal of Clinical Pathology, vol. 49, no. 8, pp. 672-675, 1996.

[38] E. Pérez-Persona, M.-B. Vidriales, G. Mateo et al., "New criteria to identify risk of progression in monoclonal gammopathy of uncertain significance and smoldering multiple myeloma based on multiparameter flow cytometry analysis of bone marrow plasma cells," Blood, vol. 110, no. 7, pp. 2586-2592, 2007.

[39] B. Paiva, M.-B. Vidriales, J. Cerveró et al., "Multiparameter flow cytometric remission is the most relevant prognostic factor for multiple myeloma patients who undergo autologous stem cell transplantation," Blood, vol. 112, no. 10, pp. 4017-4023, 2008. 


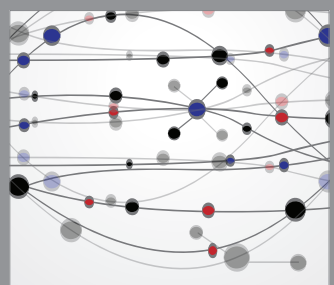

The Scientific World Journal
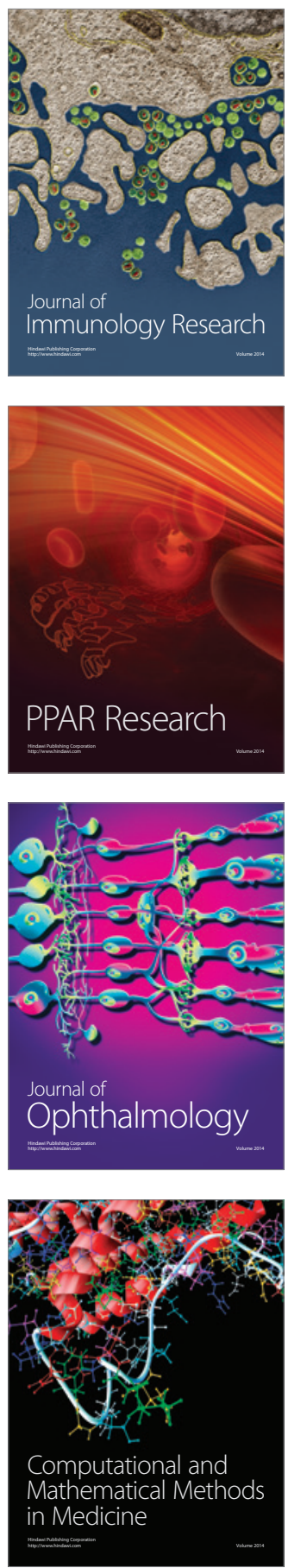

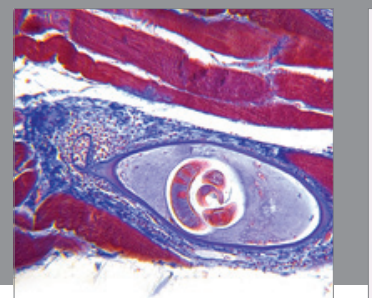

Gastroenterology

Research and Practice
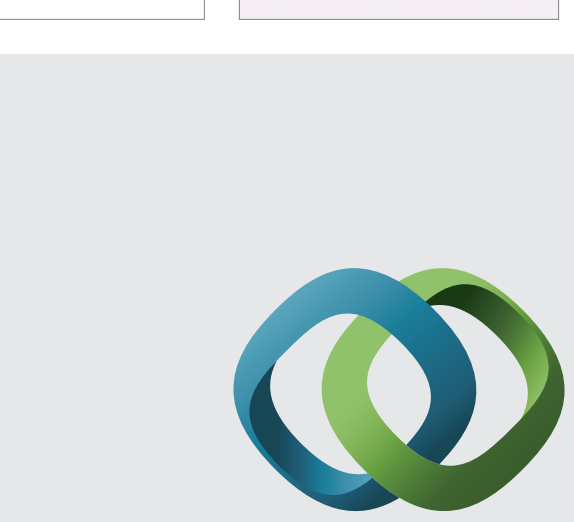

\section{Hindawi}

Submit your manuscripts at

http://www.hindawi.com
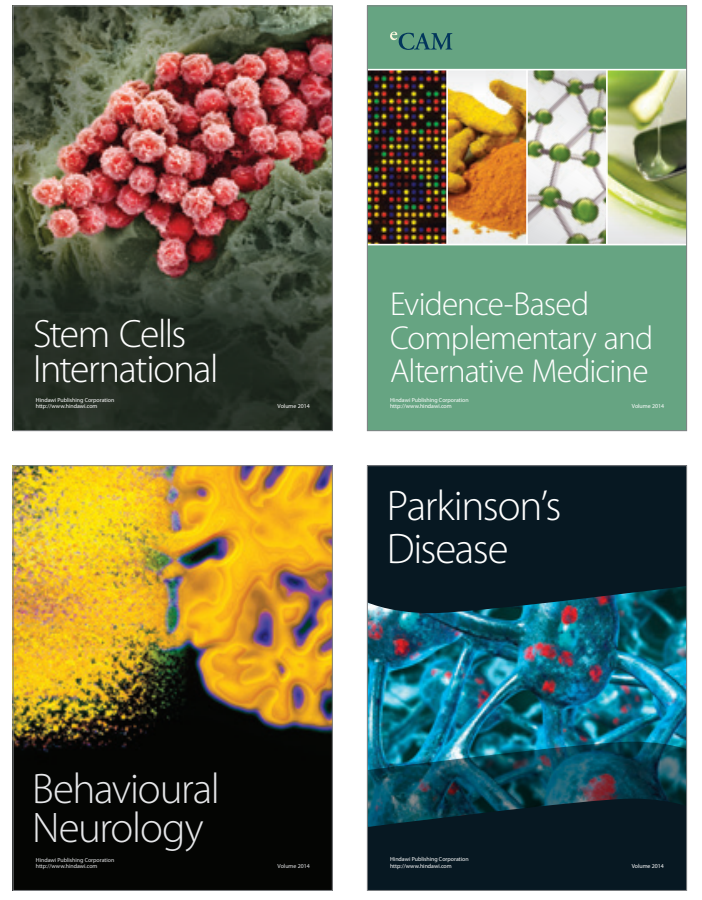
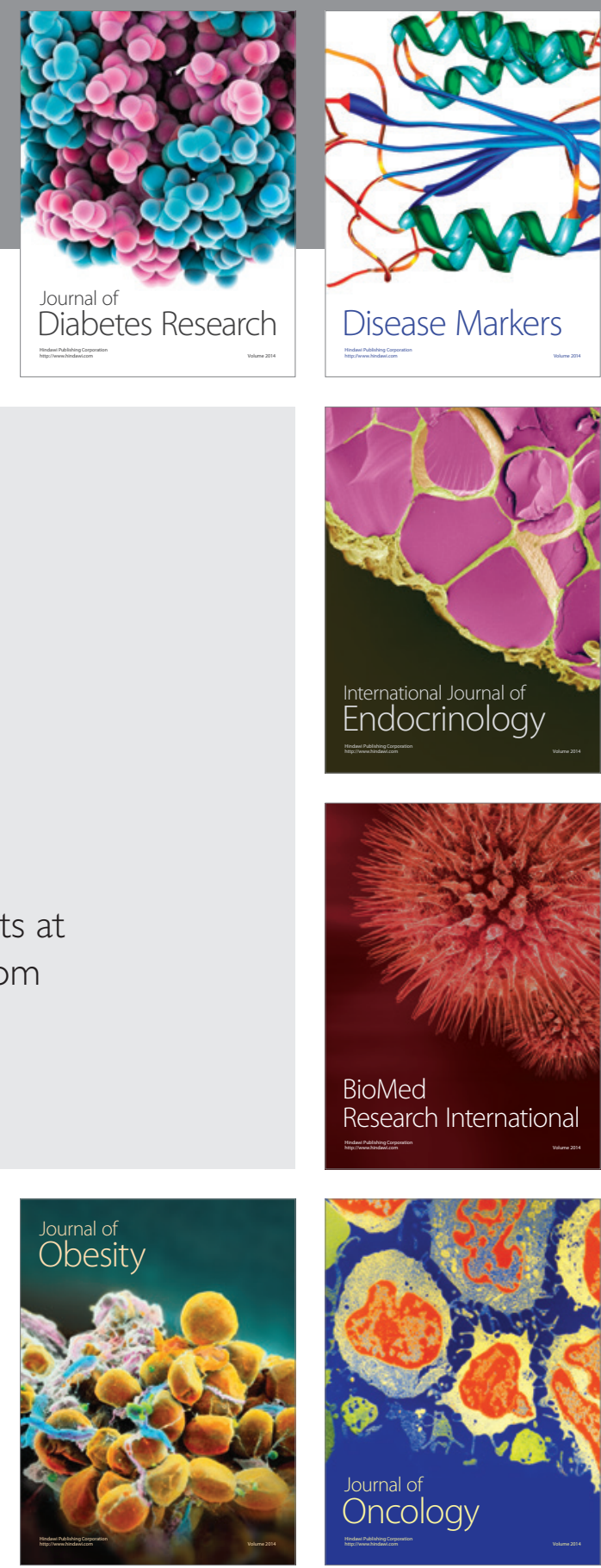

Disease Markers
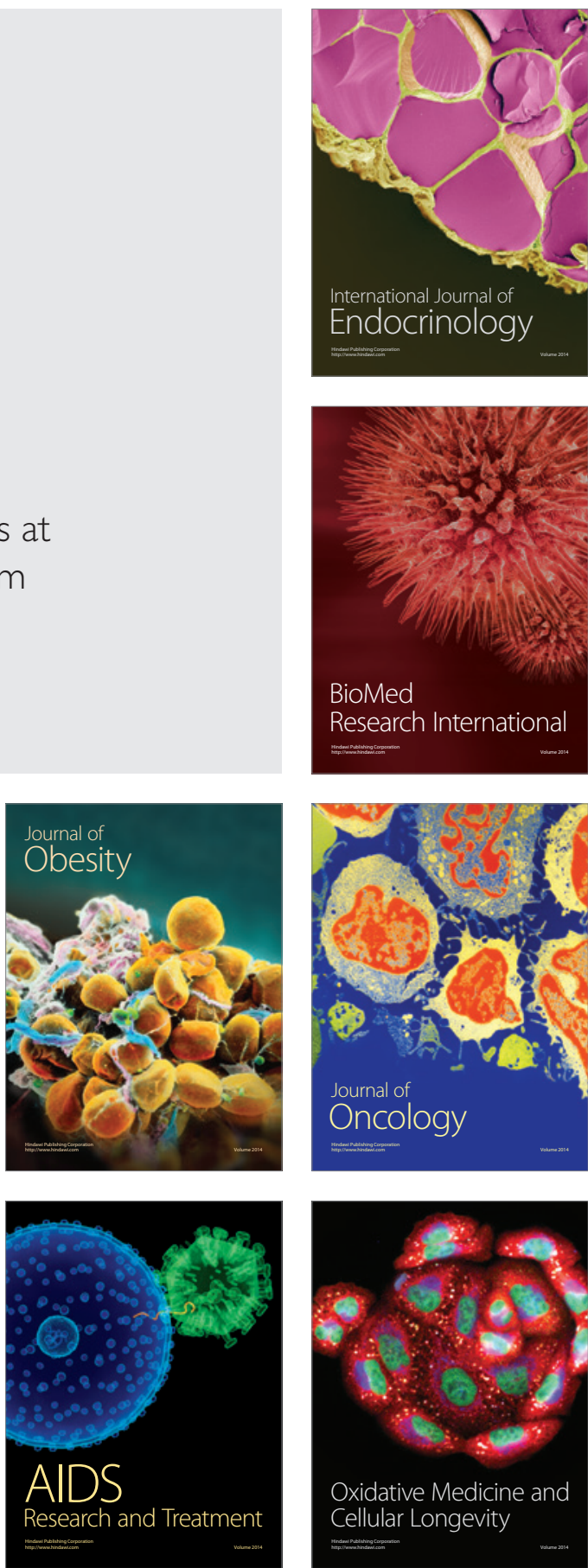